\title{
Mining For Diamonds - History and Present
}

\author{
J. Jakubec ${ }^{1}$ \\ ${ }^{1}$ SRK Consulting, Vancouver, Canada,jjakubec@srk.com
}

\section{Introduction}

Alluvial mining for diamonds started in India and for centuries Alluvial mining was the primary source of diamonds. Hard rock mining of primary kimberlite on an industrial scale had only emerged with diamond discoveries in South Africa in the 19th century. Initially, kimberlite pipes were mined as open cast mines and only within the second half of the 20th century that underground mining was implemented.

The objective of this paper is to provide an overview of modern hard rock mining methods implemented on today's diamond mines worldwide. The focus is to highlight successes and challenges with each method and compare experiences in various geographical, climate, and socioeconomic zones of the world.

\section{World Diamond Mines and Diamond Production}

According to www.mining.com and Paul Zimninsky, (1) mined diamond production is estimated to be approximately 142.3 million carats worth some $\$ 15.6$ billion. This is a $11.5 \%$ increase in carats and 9.9\% increase by value from 2016. Majority of the diamonds are being mined from primary deposits (Figure 1), mainly kimberlite and lamproite pipes. Primary mining method is still open cast mining but underground mining is becoming increasingly common.

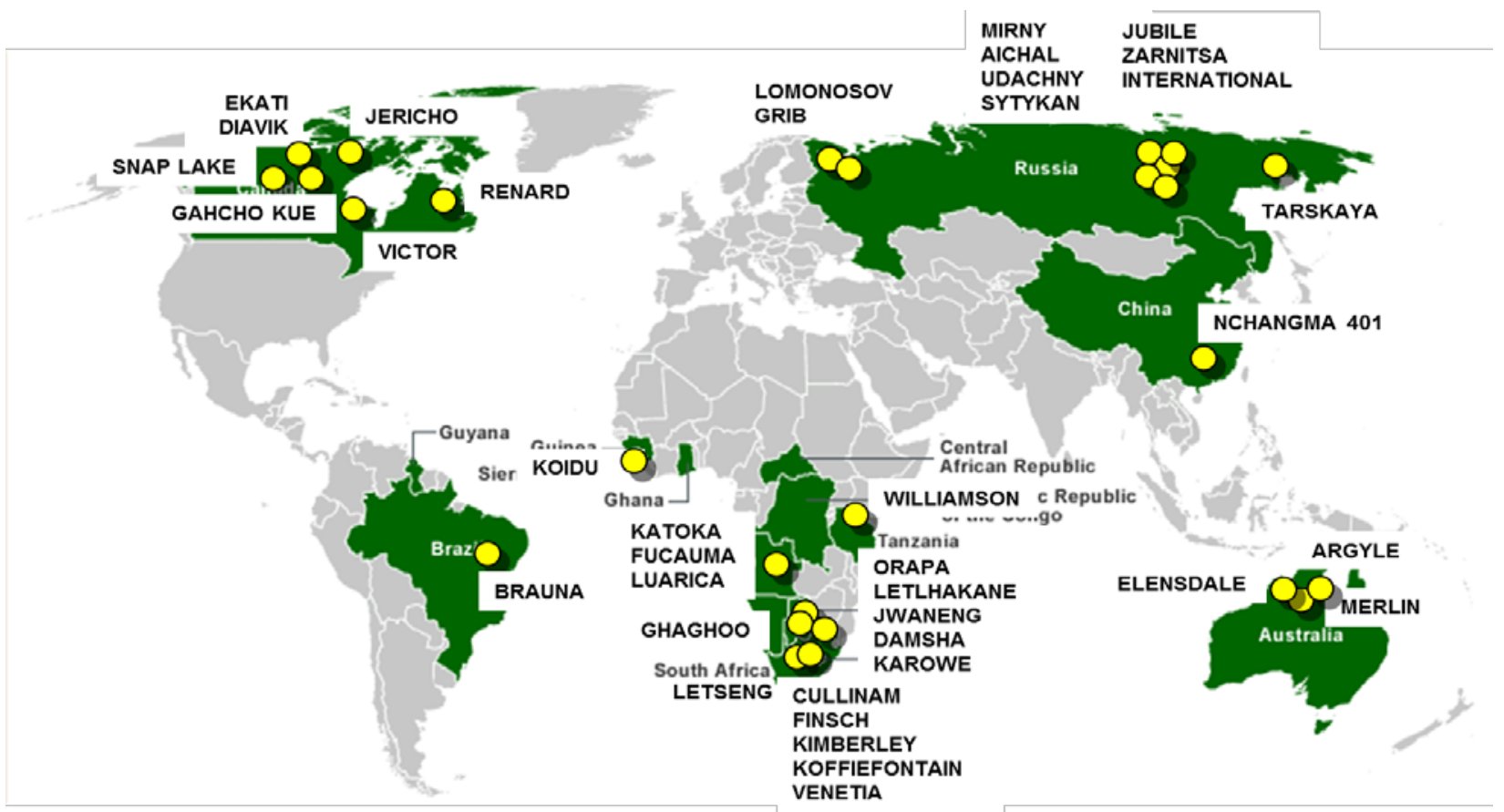

Figure 1: Main hard rock diamond mines of the world. Note that some are on care and maintenance now.

\section{Mining Methods}

Today, out of some 40 diamond hard rock mines mining kimberlite, approximately half are underground and another 20 or so have underground plans or hold the underground mining potential.

Mining methods implemented currently at hard rock diamond mines consist of two main groups: open pit and underground (Figure 2). 


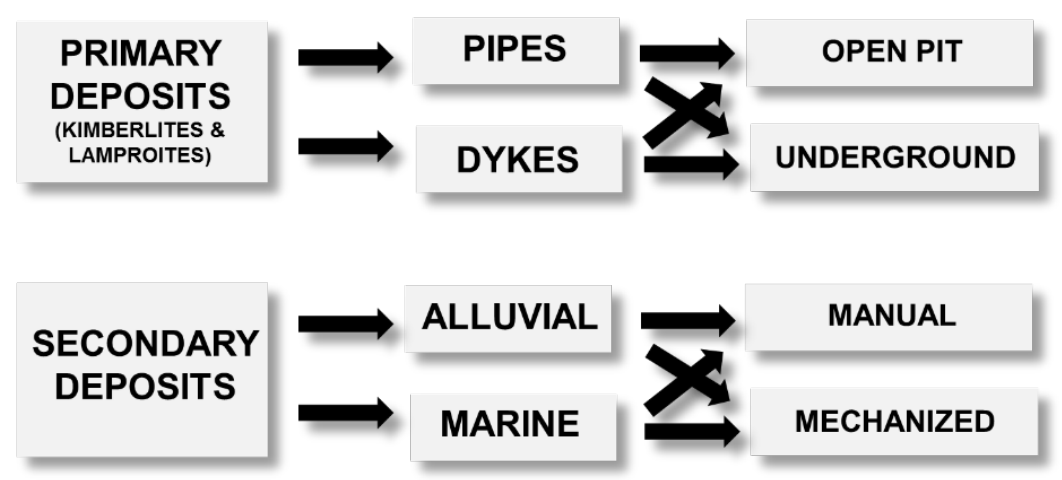

Figure 2: Main mining methods used for primary and secondary diamond deposits

For a mining project to succeed, the mining method must always be appropriate to the context of geology. This is a condition which cannot be changed and if the mining method is in conflict with this context then it will not perform as expected.

In essence, the choice of a mining method depends on the following:

- Orebody size and geometry

- NSR - value per block

- Grade distribution and dilution

- Rock mass competency

- Disturbances (stress, water)

- External constraints (corporate, market, social economic, environmental, etc.)

Open pit mining accounts today for majority of the carats produced but underground mining is playing an increased role. For example, Diavik mine although currently developing open pit A-21 project, is today fully undeground. Underground mining introduces increased complexity and operating cost, typically exeeding open pit mining cost while the production rates are significantly reduced. Figure 3 illustrates the ranges of typical mine operating costs in Northern Canada (in Canadian funds).

\begin{tabular}{ll}
\hline Direct mining cost & \\
Open pit & $\$ 5-10 / \mathrm{t}$ \\
Block caving & $\$ 10-20 / \mathrm{t}$ \\
Open benching & $\$ 20-35 / \mathrm{t}$ \\
Sublevel caving & $\$ 25-40 / \mathrm{t}$ \\
Backfill methods & $\$ 60-100 / \mathrm{t}$ \\
Processing cost & $\$ 10-20 / \mathrm{t}$ \\
Other costs (G\&A, Marketing etc) & $\$ 15-35 / \mathrm{t}$ \\
\hline
\end{tabular}

Figure 3: Northern Canada typical mine operating costs

While total typical operating costs could range from \$30-65/t for open pit mining to well over \$150/t for the backfill underground method, in reality the costs of some recent diamond projects are higher. The estimated open pit operating cost for Diavik Mine is approximately \$80-90/t (2), with \$90-100/t for Jericho Mine (2) and similar values of \$78-88/t reported for Ekati Mine (2). Operating costs for the Diavik underground operation are expected to be approximately $\$ 140 / t$ for backfill method (2), and $\$ 156 / t$ for the Snap Lake underground mine (2).

Cave mining (block, panel or incline caving and sub-level caving) and sub-level retreat accounts for majority underground mining method today.

Mining for diamonds evolved significantly from early days of open cast operations in Kimberley to modern undeground operation with fully mechanized and automated mining technology (Figure 4). 

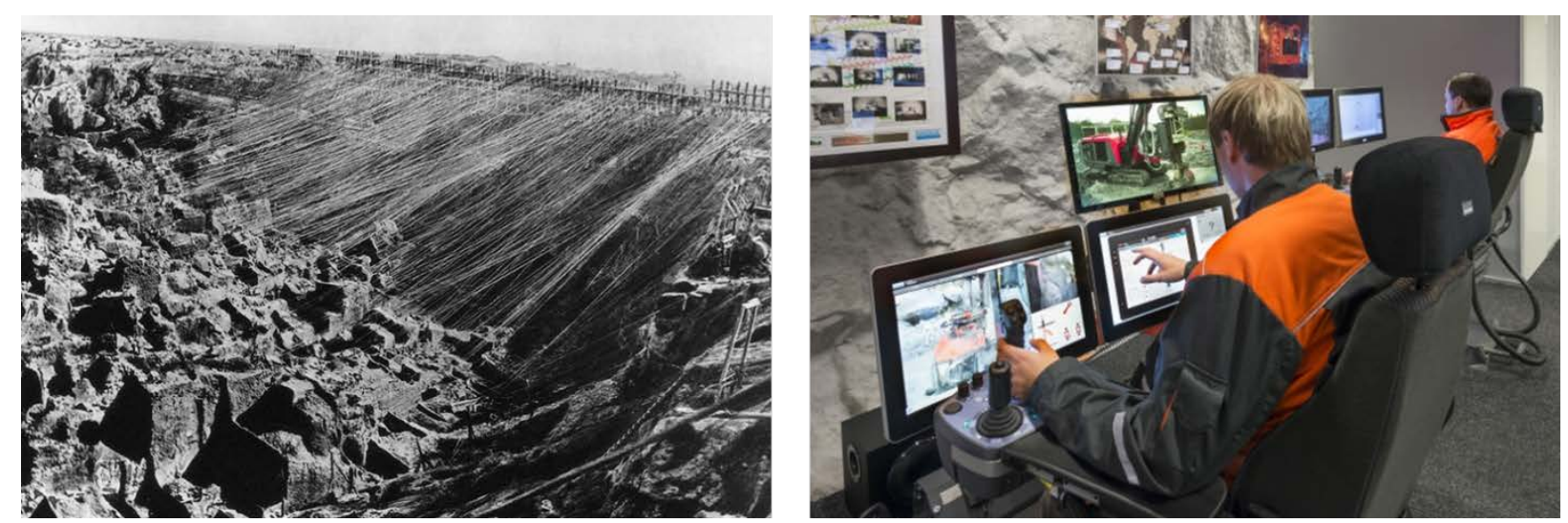

Figure 4: Early days of diamond mining in South Africa, Kimberley Diamond Mines c. 1880 (Collection of Cynthia Brantley) on the left and tele-remote operator in modern underground mine (Sandvik Tele-remote Automine)

\section{References}

1. www.mining.com/2017-global-natural-diamond-production-forecasted-142m

2. Jakubec, J., “Kimberlite Emplacement Models - The Implications for Mining Projects”, Journal of Volcanology and Geothermal Research, 2008 v. 174, iss. 1-3, pp. 20-28. 